\title{
Q\&A
}

Alan Mcnaughtan

\section{Q. Do Technology Startups Need Product Managers?}

\begin{abstract}
A. Product management is a dynamic discipline requiring a unique mix of business acumen, technological savvy, and customer-orientation. A strong productmanagement focus is critical within organizations looking to deliver best-in-class offerings to optimize profitability. But do technology startups need project managers in the very early stages of the business?
\end{abstract}

Technology startups may not have product management "in their DNA" because founding partners are often technology experts or, if they come from a business background, they may have little formal product-management experience or training. Technology entrepreneurs tend to be product-focused, which often leads to a company culture of "if you build it right, they will come". However, many startups fail due to their inability to articulate a need that their product is intended to resolve or how their product might improve performance or user experience. Products may be altered and improved by iteration, but a startup's success can be facilitated by a disciplined, customer-centric approach to product management. Technology startups that see product management as a core competency improve their chances of becoming stable and profitable organizations.

\section{What does a product manager do?}

The exact role of a product manager is difficult to define and even more so in a startup environment. According to Martin Erikson (2011; tinyurl.com/43hddh4), a project manager lives at the intersection of business, technology, and user experience. To be successful, Erikson argues, a product manager must be: an expert in one of these domains, passionate about all three of them, and constantly engaging with key stakeholders in each domain. This description of a product manager's role underscores the dynamic and varied nature of the position, spanning user experience, financial analysis, and cross-functional team management. Thus, product managers should become subject-matter and marketplace experts that are keenly attuned to customer needs and able to translate and integrate feedback into improving their products.
In The Product Manager's Desk Reference (2009; tinyurl.com/mjcpqss), Steven Haines describes product management as "the holistic business management of the product, from the time it is conceived as an idea to the time it is discontinued and withdrawn from the market". This is a more traditional description of product management; it is rooted in multi-phase, lifecycle product management. Lifecycle product management is a methodical phase/gate approach to product management where the end of each phase represents a "gate" where a specific business decision is made to proceed through to the next phase of product lifecycle.

Product management phases and gates exist to help organizations manage various product portfolios and make informed decisions about where scarce resources should be invested. Startups rarely deal with those tradeoffs. However, startup founders can be distracted by a myriad of issues as they gain momentum, and so it is even more important to have strong product-management focus on customer deployment - to interact with early adopters. Ben Yoskovitz, VP of Product at GoInstant, argues that a strong product manager is technologically savvy, metrics-orientated, and able to translate customer feedback into core product requirements that developers can focus on. Product managers need to ensure that their team is focused on the right things: the founder's vision tempered by customer feedback (Yoskovitz, 2009; tinyurl.com/m2stp8e).

Entrepreneurs tend to be serial entrepreneurs and generally have a difficult time delegating product responsibility before it is too late (Paquet, 2009; tinyurl.com/ k3ta3he). Saeed Khan, product management guru and contributor to the Pragmatic Marketing website, has argued that venture capital firms should insist on a focus on product management as part of their investment agreement. "I've seen too many cases where a CTO and a CEO are leading a company and the CTO really is technical and the CEO is very business focused and yet they fail because they don't understand how to bring those two worlds together and how to bring products to market in a scalable, efficient way" (Khan, 2009; 


\section{Do Technology Startups Need Product Managers?}

\section{Alan Mcnaughtan}

tinyurl.com/mjh4t32). Bill Campbell, former Intuit CEO, similarly supported a product management approach for startups. When asked who should follow the CEO or founder of a startup he says, "I know (it) sounds like a strange answer, Product Marketing, some people call it Product Management, but somebody who can really understand the dynamics of what goes on in a marketplace, apply technology to that marketplace, see how the technology can work, and continue to advise brilliant scientists so they can adapt their products to make sure customers are happy" (Khan, 2009; tinyurl.com/ mjh4t32).

It is not easy for a technology startup to become a stable, profitable business. Data from the Bureau of Labor Statistics in the United States suggests that twothirds of startups will fail within a decade (Shane, 2011; tinyurl.com/mzc7skl). A funding-recommendation engine called ChubbyBrain analyzed 32 unsuccessful startups to identify the top reasons for failure. The top three reasons are: i) ignored marketplace, ii) no market need, and iii) not the right team (ChubbyBrain, 2001; tinyurl.com/3bgkhbf). A product-management focus within a startup is key to validating market need, improving a product or service via customer feedback, and making sure that the founder's vision is not lost in translation.

\section{Case study: Wesabe}

A great way to underscore the importance of a customer-focused product manager within a technology startup is to look at how Wesabe (wikipedia.org/wiki/Wesabe) lost its first-mover advantage in the personal-finance industry to Mint (mint.com).

Wesabe was at the forefront of the Web 2.0 explosion when online experiences moved beyond static data to interactive experiences tailored to specific users. Launched in November 2006, Wesabe was a site dedicated to helping people manage personal finances. It aggregated a user's financial data online and made recommendations based on the data to improve the user's financial position. It was a great idea at the right time - Wesabe preceded Mint by almost a full year - so, where did it all go wrong for them?

Like many technology startups, Wesabe was co-founded by two friends: Marc Hedlund (Chief Product Officer) and Jason Knight (CEO). As CPO, Marc made almost all product decisions relating to Wesabe's service. When Jason Knight was forced to step down due to family illness, it was Mark Hedlund at the helm, guiding Wesabe through the final two years of its existence.
According to Hedlund (2010; tinyurl.com/l8lluqy), there are two fundamental reasons for Wesabe's demise. First, Wesabe made a strategic error relating to a "build vs. buy" decision. At the time, Yodlee (yodlee.com) was the clear leader in financial data-aggregation services. They were, however, not in great shape financially. Wesabe did not want to tie themselves to a single provider with a poor financial outlook, so they decided to build their own data-acquisition systems, which never worked as well as Yodlee's. Their decision to build rather than leverage a proven technology was a mistake.

The second reason that assured Wesabe's would lose credibility and market share to Mint had to do with the product itself. Wesabe's ultimate goal was to provide a tool for their users to interact with their own financial data; they were trying to make usability and editing of data as intuitive as possible in an attempt to get customers to change their behaviours. Mint, on the other hand, was creating a product where customers did not actually have to do any work to interact with their financial data. Mint automatically categorized all of a user's financial data and transactions; they also made signup painless. In short, Mint had a better user experience and actually addressed a core customer need that improved the lives of its users: they provided a simple solution to aggregate and sort financial transactions.

Marc Hedlund's company had a significant first-mover advantage. And, he had a clear vision: to help users improve their financial personal-finance management and decision-making. The whole company took on Marc's view that "if they build it, they will come". Neither Marc nor any of the Wesabe team ever took a customer-centric product-management approach to see what users really required. Instead, they addressed what Wesabe thought were the customers' needs. In the end, their product was far too complex for an average user. Mint provided a simple and easy-to-use tool to aggregate personal finances and did it in a slick and intuitive way. It is not a coincidence that it was Mint that was acquired by Intuit, not Wesabe, given the importance Intuit Chairman and former CEO Bill Campbell places on product-driven startups that identify and then solve specific customer needs.

\section{Conclusion}

Serial entrepreneurs are aware that launching a successful startup is difficult. Failure can be traced back to not understanding a target market or there being no market need for a specific product. Further complicat- 


\section{Do Technology Startups Need Product Managers?}

\section{Alan Mcnaughtan}

ing the path to success are founders who are biased towards a "build it and they will come" attitude. Startups that bring in a strong product-management leader early in their lifecycle will have a higher probability of success. Venture capital firms would be wise to mandate a senior product-management position as a stipulation of funding so that sufficient focus is placed on understanding marketplace dynamics to ensure that there is a current or imminent need for a new product. The presence of a strong product manager may ensure a metrics-oriented approach to obtaining and analyzing customer feedback to create product requirements that can actually solve specific customer needs rather than an unproven vision.

\section{Recommended Reading}

- The Product Manager's Desk Reference by Steven Haines (2009; tinyurl.com/mjcpqss)

- 42 Rules of Product Management by Brian Lawley and Greg Cohen, eds. (2012; tinyurl.com/mqbjsca)

- Inspired: How To Create Products Customers Love by Marty Cagan (2008; tinyurl.com/klck5oq)

\section{About the Author}

Alan Mcnaughtan is a Product Manager for Residential Internet Access Services at Bell Canada. He supports a team of Product Managers focused on developing and improving products across Bell's Internet portfolio. Core portfolios include Bandwidth Management, Internet VAS portfolios (email, security, and usage) and overall Internet strategy for Bell Residential Services. Alan has an MBA from Griffith University in Brisbane, Australia, and a BAH from Queen's University in Kingston, Canada. Alan is an active member of the Broadband Multimedia Marketing Association (BMMA) and the Ottawa Product Management Association (OPMA).

Citation: Mcnaughtan, A. 2013. Q\&A. Do Technology Startups Need Product Managers? Technology Innovation Management Review. June 2013: 39-41.

(cc) BY

Keywords: product management, product manager startups, Wesabe, Mint 